\title{
The effect of increased ambient temperature on thermoregulatory responses in spinal cord injured people
}

\author{
Tamae Yoda ${ }^{1,2^{*}}$, Katy E Griggs ${ }^{2}$, Christof A Leicht ${ }^{2}$, Victoria L Goosey-Tolfrey ${ }^{2}$ \\ From 15th International Conference on Environmental Ergonomics (ICEE XV) \\ Portsmouth, UK. 28 June - 3 July 2015
}

\begin{abstract}
Introduction
Individuals with a spinal cord injury (SCI) have impaired autonomic thermoregulation, causing a loss of vasomotor control and sweating below the level of lesion due to the disruption of the sympathetic nervous system. Their change in body core temperature can therefore be more pronounced than in able-bodied individuals when they face thermal challenges, such as experienced in the heat, cold or during exercise. Consequently, for individuals with a SCI it is important to be able to control body temperature with behavioural thermoregulation which is influenced by thermal comfort and sensation. The aim of the present study was to evaluate the effect of increased ambient temperature on thermoregulatory responses and perceptual responses of thermal sensation and comfort in individuals with a SCI.
\end{abstract}

\section{Methods}

Eight participants with a SCI (4 tetraplegia and 4 paraplegia) and 8 able-bodied (AB) participants volunteered for this study. Participants rested in a chair in an environmental chamber for the duration of the experiment. Ambient temperature in the chamber was kept at $27.5^{\circ} \mathrm{C}$ for 20 minutes and was then gradually increased to $40^{\circ} \mathrm{C}$ during 50 minutes, increasing by $2.5^{\circ} \mathrm{C}$ every 10 minutes. Gastrointestinal temperature was measured by a telemetry pill $\left(\mathrm{T}_{\mathrm{gi}}\right)$. Skin temperature at ten sites and skin blood flow (skBF) were measured throughout the experiment. Thermal sensation and thermal comfort were reported by participants every 5 minutes using visual analogue scales.

* Correspondence: yoda72@dokkyo.ac.jp

${ }^{1}$ Department of International Liberal Arts, Dokkyo University, Soka, Japan Full list of author information is available at the end of the article

\section{Results}

$\mathrm{T}_{\mathrm{gi}}$ baseline values were similar between $\mathrm{SCI}$ and $\mathrm{AB}$ (mean (SD) $37.0(0.5){ }^{\circ} \mathrm{C}$ and $37.1(0.2){ }^{\circ} \mathrm{C}$ for SCI and $\mathrm{AB}$, respectively, $\mathrm{p}>0.05)$. At the end of the experiment, there was no change in $\mathrm{T}_{\mathrm{gi}}$ from baseline in either group $\left(37.2(0.3){ }^{\circ} \mathrm{C}\right.$ and $37.1(0.3){ }^{\circ} \mathrm{C}$ for $\mathrm{SCI}$ and $\mathrm{AB}$, respectively, $\mathrm{p}>0.05)$. The forehead temperature in both groups was elevated similarly as the ambient temperature increased $(\mathrm{p}>0.05)$. Thigh and calf temperatures were lower in $\mathrm{SCI}$ than in $\mathrm{AB}$ throughout the experiment $(\mathrm{p}<0.05)$. Mean skin temperature at baseline was lower in SCI than in $\mathrm{AB}\left(32.9(0.4){ }^{\circ} \mathrm{C}\right.$ vs $\left.33.7(0.5){ }^{\circ} \mathrm{C}, \mathrm{p}<0.05\right)$. Mean skin temperature remained lower in $\mathrm{SCI}$ than $\mathrm{AB}$ as ambient temperature increased $(p<0.05)$. Change in skBF at the forehead during heat exposure was similar between the groups ( $p>0.05$ ), whilst skBF at the thigh was higher in $A B$ $(\mathrm{p}<0.05)$. Thermal sensation and comfort were similar in both groups from baseline to the end of the heat exposure $(\mathrm{p}>0.05)$. Thermal comfort scores decreased to "uncomfortable" in both groups with increasing ambient temperature.

\section{Discussion}

$\mathrm{T}_{\mathrm{gi}}$ in SCI remained unchanged, however the measured skin temperature sites showed greater variation in SCI than in AB. This may be explained by the lack of autonomic thermoregulation below the level of lesion. Importantly, SCI participants could sense the change of ambient temperature equally well as $\mathrm{AB}$ participants. Possibly, the remaining sensate area, that depends on the level of lesion, provides sufficient sensory feedback for thermal sensation. It has been reported that the face has a preferential thermosensitivity to temperature sensation [1], therefore intact sensation of the face in SCI 
may play an important role to induce thermoregulatory behaviour.

\section{Conclusion}

These data suggest that individuals with a SCI are able to sense the change in ambient temperature, which should allow them to control body temperature behaviourally. Further research is needed to explain how the level of the lesion affects these sensations.

\section{Authors' details}

${ }^{1}$ Department of International Liberal Arts, Dokkyo University, Soka, Japan.

2Peter Harrison Centre for Disability Sport, Loughborough University,

Loughborough, UK.

Published: 14 September 2015

\section{Reference}

1. Cotter, Taylor: J Physiol 2005, 565:335-345.

doi:10.1186/2046-7648-4-S1-A157

Cite this article as: Yoda et al:: The effect of increased ambient

temperature on thermoregulatory responses in spinal cord

injured people. Extreme Physiology \& Medicine 2015 4(Suppl 1):A157.

Submit your next manuscript to BioMed Central and take full advantage of:

- Convenient online submission

- Thorough peer review

- No space constraints or color figure charges

- Immediate publication on acceptance

- Inclusion in PubMed, CAS, Scopus and Google Scholar

- Research which is freely available for redistribution

Submit your manuscript at www.biomedcentral.com/submit
C Biomed Central 